\title{
Herança da resistência do mamoeiro a doenças fúngicas com base em análise dialélica de Hayman
}

\author{
Marcelo Vivas ( $\left.{ }^{1 *}\right)$; Silvaldo Felipe da Silveira ( $\left.{ }^{1}\right)$; Antonio Teixeira do Amaral Junior ( $\left.{ }^{2}\right)$; \\ Deisy Lúcia Cardoso ( $\left.{ }^{2}\right)$; Messias Gonzaga Pereira ( $\left.{ }^{2}\right)$ \\ (1) Universidade Estadual do Norte Fluminense Darcy Ribeiro (UENF), Laboratório de Entomologia e Fitopatologia, Av. Alberto \\ Lamego, 2000, Pq. Califórnia, 28013-602, Campos dos Goytacazes (RJ), Brasil. \\ (2) UENF, Laboratório de Melhoramento Genético Vegetal, Campos dos Goytacazes (RJ), Brasil. \\ $\left({ }^{*}\right)$ Autor correspondente: mrclvivas@hotmail.com
}

Recebido: 29/abr./2013; Aceito: 31/out./2013

\begin{abstract}
Resumo
Neste trabalho foram estimados parâmetros genéticos e estudou-se a herança da resistência do mamoeiro às doenças pintapreta, oídio e mancha-de-phoma, em cruzamentos dialélicos no campo. Avaliaram-se 56 combinações ( $F_{1}$ s e recíprocos) e oito genitores, quatro do grupo Formosa (Maradol, JS12-N, JS12-4 e Sekati) e quatro do grupo Solo (Waimanalo, Golden, Sunrise Solo 72-12 e São Mateus). Quantificaram-se a severidade de pinta-preta em folha e em fruto, e a severidade de oídio e manchade-phoma em folha. Efetuou-se análise de variância conjunta dos dados, considerando-se, além dos cruzamentos, a época de avaliação como fontes de variação. A severidade de pinta-preta em folha e em fruto e a severidade de oídio em folha tiveram ausência de significância nos três testes de suficiência do modelo aditivo-dominante. Observou-se a existência de pelo menos quatro genes ou blocos gênicos com dominância para severidade de oídio e ao menos um para severidade de pinta-preta em folha e fruto. Para severidade de oídio, os efeitos gênicos aditivos foram mais importantes. Efeitos gênicos aditivos e não aditivos, por sua vez, foram igualmente importantes tanto para severidade de pinta-preta em folha, quanto para severidade em fruto. Constatou-se efeito de dominância parcial para severidade de oídio e dominância completa para severidade de pintapreta em folha e em fruto. Sekati foi o genitor que apresentou a maior concentração de alelos favoráveis para a redução da severidade de pinta-preta e de oídio.
\end{abstract}

Palavras-chave: Asperisporium caricae, Streptopodium caricae, Carica papaya, hibridação.

\section{Inheritance of papaya resistance to fungal disease based on Hayman's diallel analysis}

\begin{abstract}
This study aimed to estimate genetic parameters and to study the inheritance of resistance to papaya black-spot, powderymildew and phoma-spot through diallel cross on a field plot experiment. The 56 hybrid combinations (F1's and reciprocals) and eight genotypes of papaya, four of 'Formosa' group ('Maradol', 'JS12-N', 'JS12-4' and 'Sekati') and four of the 'Solo' group ('Waimanalo', 'Golden', 'Sunrise Solo 72-12' and 'São Mateus') were evaluated. The severities of black spot on leaf and fruit and the severity of powdery mildew and phoma spot in leaf were quantified. The analyses of variance of the data were performed considering the intersections and the season (evaluation date) as sources of variation. The severity of black-spot on leaf and fruit and the severity of powdery-mildew had absence of significance concerning the three tests of sufficiency for the additive dominant model. The estimated numbers of genes or gene blocks with dominance indicated the existence of at least four genes or gene blocks to severity of powdery mildew and at least one for severities of black-spot on leaf and fruit. For severity of powdery mildew additive gene effects were more important. Additives and non-additives gene effects were important to the severities of black-spot on leaf and fruit. It was observed effect of partial dominance for severity powdery mildew and complete dominance for severities of black-spot on leaf and fruit. The parent 'Sekati' presented the highest concentration of favorable alleles for the reduction of the black-spot and powdery mildew.
\end{abstract}

Key words: Asperisporium caricae, Streptopodium caricae, Carica papaya, hybridization.

\section{INTRODUÇÃO}

Entre os desafios a serem superados pela cultura do mamoeiro (Carica papaya L.), ressalta-se a necessidade de genótipos comerciais resistentes às doenças. Durante o seu ciclo produtivo, o mamoeiro é suscetível a inúmeras doenças de etiologia fúngica. O oídio - Streptopodium caricae Liberato e Barreto, a pinta-preta - Asperisporium caricae (Speg.) Maubl e a mancha-de-phoma - Stagonosporopsis caricae (Sydow \& P. Sydow) Aveskamp, Gruyter \& Verkley [= Phoma caricae-papayae (Tarr.) Punith; Ascochyta caricaepapayae Tarr.] são exemplos de algumas doenças comumente 
observadas em mamoeiros, ocasionando perdas econômicas (Liberato et al., 2004; Rezende e Martins, 2005).

Como inexistem genótipos resistentes a essas doenças (DiAnese et al., 2007; Vivas et al., 2010a; 2012c), a pulverização com fungicidas tornou-se a principal medida de controle empregada. Porém, resíduos de agrotóxicos têm sido um entrave à exportaçáo de mamão e a dependência da cultura com relação ao controle químico convencional acarreta em marketing negativo à exportação de frutas brasileiras. Já o plantio de variedades resistentes às doenças obtidas por melhoramento genético desponta como uma alternativa atraente para a produçáo sustentável da cultura, com menor impacto ao meio ambiente. Embora já existam trabalhos relatando a variabilidade genética para características que conferem resistência a doenças em genótipos de mamoeiro (DiAnese et al., 2007; Vivas et al., 2010a; 2012c), há necessidade de estudos visando o entendimento da natureza e do controle genético para tais características.

O conhecimento da natureza e do controle genético de uma característica é fundamental para a condução eficiente de um programa de melhoramento, orientando a escolha do melhor procedimento de seleção e dos métodos de melhoramento mais eficientes na condução das populaçôes segregantes (Cruz et al., 2012; VencovsKy e Barriga, 1992). Entre as diferentes metodologias existentes, os cruzamentos dialélicos se destacam. Cruz et al. (2012) mencionam diferentes metodologias para analisar os dialélos, dentre as quais destacam-se as metodologias propostas por GARDNER e Eberhart (1966); Griffing (1956) e Hayman (1954a,b). A metodologia de Hayman (1954a,b) não se baseia em modelos previamente estabelecidos, mas no conhecimento da natureza ambiental e genética de estatísticas (médias, variâncias, covariâncias) obtidas a partir de uma tabela dialélica, fornecendo informaçóes sobre o controle genético da característica em estudo, dos valores genéticos dos genitores e dos limites de seleção de cada característica (Cruz et al., 2012; Vencovsky e Barriga, 1992).

A despeito das análises dialélicas, no que tange à resistência genética a doenças, há trabalhos que utilizaram a análise proposta por GRIFFING (1956) para estimar a ação gênica e as capacidades específicas e geral de combinação para resistência a pinta-preta, oídio e mancha-de-phoma (VIVAS et al., 2012a,b; 2013). Entretanto, a metodologia proposta por Hayman (1954a,b) e Jinks e Hayman (1953) fornece informaçôes sobre importantes parâmetros genéticos, não obtidos pela metodologia de GrifFIng (1956), tais como o grau médio de dominância, número de genes ou blocos gênicos envolvidos na manifestação da característica, distribuição dos alelos nos genitores, herdabilidades no sentido amplo e restrito, bem como se obtém um indicativo dos limites teóricos de seleção. Portanto, este trabalho, pioneiro no estudo de herança em mamoeiro utilizando análise dialélica de Hayman, teve por objetivo, além de determinar o controle gênico, obter estimativas dos parâmetros genéticos supracitados, de características relacionadas à resistência de mamoeiro a oídio, pinta-preta e mancha-de-phoma.

\section{MATERIAL E MÉTODOS}

O experimento foi implantado no ano de 2009, na empresa Caliman Agrícola S/A, em Linhares, ES. As 56 combinaçóes ( $\mathrm{F}_{1} \mathrm{~s}$ e recíprocos) mais os oito genitores, quatro do grupo Formosa (Maradol, JS12-N, JS12-4 e Sekati) e quatro do grupo Solo (Waimanalo, Golden, Sunrise Solo $72-12$ e São Mateus), foram avaliadas em delineamento de blocos ao acaso, com quatro repetiçóes, sendo cada parcela composta por 10 plantas (duas fileiras de cinco plantas cada), no espaçamento $2,0 \times 1,8 \mathrm{~m}$. Entre tratamentos, lateralmente, adotou-se o espaçamento de 3,6 m.

A parcela útil consistiu de três plantas centrais, selecionadas com base na presença de flores hermafroditas. Quantificaramse, em março e maio de 2010, com o auxílio de escala diagramática, as severidades de mancha-de-phoma, pinta-preta e oídio em folha (SANTOs et al., 2011; VIVAS et al., 2010a; 2012c), bem como a severidade de pinta-preta em fruto (VIVAs et al., 2010b). A severidade de mancha-de-phoma foi estimada na folha localizada abaixo da folha com a axila do pecíolo anexo a flor recém-aberta. A severidade de oídio e de pinta-preta em folha foram estimadas na folha com a axila do pecíolo anexa a flor recém-aberta. A severidade de pinta-preta em fruto foi estimada no fruto em estádio 1 de maturação (início de manchas amareladas na casca).

Efetuou-se análise de variância conjunta dos dados, considerando-se, além dos cruzamentos, a época de avaliação como fontes de variação. Quando constatado efeito significativo da interação genótipo $\times$ época, foram realizadas análises separadas para cada época. Quando não constatada significância da interação, trabalhou-se com as médias das duas avaliações.

O uso do método proposto por HaYman (1954a,b) e Jinks e Hayman (1953) exige as seguintes pressuposiçóes: segregação diplóide; genitores homozigóticos; ausência de efeito materno; ausência de alelismo múltiplo; genes distribuídos independentemente entre os genitores; e ausência de epistasia. De maneira conjunta, as falhas nas pressuposiçóes foram avaliadas por testes de suficiência do modelo aditivo-dominante (CRUZ et al., 2012).

Nas variáveis que evidenciaram a viabilidade de utilização do modelo aditivo-dominante no estudo genético foram estimados, a partir das estatísticas obtidas da tabela dialélica, os seguintes componentes genéticos e ambientais: $\hat{\varepsilon}$ - componente de variância ambiental; $\hat{\mathrm{D}}$ - componente de variância associado aos efeitos aditivos; $\hat{\mathrm{H}}_{1}$ e $\hat{\mathrm{H}}_{2}$ - componentes de variância associados aos desvios de dominância; $\hat{\mathrm{h}}^{2}$ - componente quadrático determinado pela diferença de média entre híbridos e pais; $\hat{\mathrm{F}}$ - componente associado à covariância entre efeitos 
aditivos e não aditivos; e $\hat{\mathrm{D}}-\hat{\mathrm{H}}_{1}$ - componente que expressa a diferença entre efeitos gênicos aditivos e dominantes.

Também foram estimados os seguintes parâmetros genéticos: $\sqrt{\hat{\mathrm{H}}_{1} / \hat{\mathrm{D}}}$ - grau médio de dominância; $\hat{\mathrm{H}}_{2} / 4 \hat{\mathrm{H}}_{1}$ - distância dos alelos (simetria); $\hat{\mathrm{K}}_{\mathrm{D}} / \hat{\mathrm{K}}_{\mathrm{R}}$ - relação dominante/recessivo; $\hat{\mathrm{h}}^{2} / \hat{\mathrm{H}}_{2}$ - número de genes com dominância; $\hat{\mathrm{h}}_{\mathrm{R}}^{2}$ - coeficiente de determinação no sentido restrito; $\hat{\mathrm{h}}_{\mathrm{A}}^{2}$ - coeficiente de determinação no sentido amplo; correlaçôes entre os valores médios dos genitores $\left(\overline{\mathrm{Y}}_{\mathrm{rr}}\right)$ e da soma da covariância, entre médias dos genitores e médias da r-ésima linha $\left(\hat{\mathrm{W}}_{\mathrm{r}}\right)$, e da variância entre médias da r-ésima linha $\left(\hat{\mathrm{V}}_{\mathrm{r}}\right)$; valores esperados das coordenadas $\hat{\mathrm{W}}_{\mathrm{R}} ; \hat{\mathrm{V}}_{\mathrm{R}}$ e $\hat{\mathrm{W}}_{\mathrm{D}} ; \hat{\mathrm{V}}_{\mathrm{D}}$; e valor predito para o genitor com máxima concentração de alelos dominantes $\left(\hat{\mathrm{Y}}_{\mathrm{D}}\right)$ e recessivos $\left(\hat{\mathrm{Y}}_{\mathrm{R}}\right)$. O significado dos componentes e parâmetros é explicado por CRUz et al. (2012) e Hayman (1954b). Todas as análises foram feitas utilizando os recursos computacionais do programa GENES (Cruz, 2013).

\section{RESULTADOS E DISCUSSÃO}

Das variáveis avaliadas, observou-se efeito significativo de todas as fontes de variação testadas (genótipo, época de avaliação e interação entre os dois fatores) para severidade de pinta-preta em folha e em fruto e para severidade de mancha-de-phoma em folha. Dessa forma, procederam-se análises individuais, para cada época de avaliação. Por outro lado, para severidade de oídio em folha não foi observado efeito da interação genótipo x época, assim os dados médios das duas épocas de avaliação foram utilizados para as análises individuais.

Considerando as análises de variâncias individuais, observou-se que para severidade de oídio e de mancha-dephoma na primeira e na segunda épocas, houve significância do efeito de genótipos a 5\% de significância pelo teste $\mathrm{F}$. Já para severidade de pinta-preta em folha observou-se efeito significativo de genótipo apenas na segunda época de avaliação e, portanto, para severidade de pinta-preta em folha apenas a segunda época foi considerada nas análises. Por sua vez, para pinta-preta em fruto houve efeito significativo de genótipo apenas na primeira época de avaliação, assim, para essa característica, apenas a primeira época foi considerada nas análises.

As restrições impostas na utilização do método de HaYMAN (1954a,b) foram avaliadas por testes de suficiência do modelo aditivo-dominante, com base na heterogeneidade de $\hat{\mathrm{W}}_{\mathrm{i}}-\hat{\mathrm{V}}_{\mathrm{i}}$. Na Tabela 1 são apresentados os resultados da aplicação de três testes na avaliação da adequação dos dados ao modelo aditivo-dominante das características avaliadas. A severidade de pinta-preta em folha e em fruto, bem como a severidade de oídio em folha, revelaram ausência de significância nos três testes, evidenciando a adequação às restrições impostas e a viabilidade de utilização do modelo aditivo-dominante (Tabela 1). Nas demais características, a ocorrência de significância em pelo menos um dos testes do modelo aditivo-dominante evidenciou a não adequação do modelo. Em razão disso, foram excluídos das análises seguintes as severidades de mancha-de-phoma avaliadas na primeira época e na segunda época.

A estimativa do grau médio de dominância $\left(\sqrt{\hat{\mathrm{H}}_{1} / \hat{\mathrm{D}}}\right)$ de 0,37 , para severidade de oídio, indicou a existência de dominância parcial entre os alelos que atuam no controle genético da característica que confere resistência a oídio (Tabela 2), o que também pode ser verificado graficamente, na reta de regressão de $\hat{\mathrm{W}}_{\mathrm{r}}$ em $\hat{\mathrm{V}}_{\mathrm{r}}$ (Figura 1a). Diferentemente do observado para severidade de oídio, quando se analisa o grau médio de dominância $\left(\sqrt{\hat{\mathrm{H}}_{1} / \hat{\mathrm{D}}}\right)$ para características relacionadas à severidade de pinta-preta em folha e em fruto, observaram-se valores próximos da unidade para as duas variáveis, o que caracteriza a dominância completa como o principal efeito na expressão dessas características (Tabela 2). $\mathrm{O}$ mesmo pode ser observado na reta de regressão de $\hat{W}_{\mathrm{r}}$ em $\hat{V}_{\mathrm{r}}$ (Figura 1b,c).

Para as características SOM, SPP e PPF, as estimativas da estatística $\hat{\mathrm{K}}_{\mathrm{D}} / \hat{\mathrm{K}}_{\mathrm{R}}$ permitem inferir que a expressão gênica é controlada por genes dominantes, o que é corroborado pela predominância de genes dominantes na expressão para as três variáveis (Tabela 2, Figura 1). As estimativas dos números de genes ou blocos gênicos com dominância $\left(\hat{\mathrm{h}}^{2} / \hat{\mathrm{H}}_{2}\right)$ indicaram

Tabela 1. Resultados do teste de suficiência do modelo genético aditivo-dominante com base na análise de variância dos valores de $\hat{\mathrm{W}}_{\mathrm{r}}-\hat{\mathrm{V}}_{\mathrm{r}} \mathrm{e}$ na análise da regressão linear de $\hat{\mathrm{W}}_{\mathrm{r}}$ em função de $\hat{\mathrm{V}}_{\mathrm{r}}$, na severidade de oídio (SOM), de mancha-de-phoma (SMP1 e SMP2, respectivamente, primeira e segunda avaliaçáo) e de pinta-preta em folha (SPP) e em fruto (PPF), segundo o método de HaYMAN (1954a,b)

\begin{tabular}{|c|c|c|c|c|}
\hline \multirow{2}{*}{ Caráter } & Anova $\left(\hat{\mathrm{W}}_{\mathrm{i}}-\hat{\mathrm{V}}_{\mathrm{i}}\right)$ & \multicolumn{3}{|c|}{ Regressão $W_{i}=1 / 4\left(D-H_{1}\right)+b V_{i}$} \\
\hline & QM (Linhas) & $\hat{\mathrm{b}} \pm$ Variância & $t\left(H_{0}: b=1\right)$ & $t\left(H_{0}: b^{\prime}=0\right)$ \\
\hline SOM & $0,0109 n s$ & $0,836 \pm 0,021$ & $-1,143 n s$ & $-1,099 \mathrm{~ns}$ \\
\hline SMP1 & $0,5463 \mathrm{~ns}$ & $0,683 \pm 0,014$ & $-2,713^{*}$ & 0,531ns \\
\hline SMP2 & $0,7295 \mathrm{~ns}$ & $0,600 \pm 0,009$ & $-4,122 * *$ & $1,841 \mathrm{~ns}$ \\
\hline SPP & $0,0024 n s$ & $0,810 \pm 0,030$ & $-1,108 \mathrm{~ns}$ & $-1,575 \mathrm{~ns}$ \\
\hline PPF & $0,0088 \mathrm{~ns}$ & $0,999 \pm 0,004$ & $-0,015 n s$ & $-0,941 \mathrm{~ns}$ \\
\hline
\end{tabular}

ns: Não significativo; ${ }^{*} \mathrm{e}^{* *}$ Significativo, respectivamente, ao nível de 5 e $1 \%$ pelos teste $\mathrm{F}$ e, ou pelo teste $\mathrm{t}$ 
Tabela 2. Estimativas dos parâmetros genéticos e não genéticos da severidade de pinta-preta em folha (SPP) avaliada na segunda época, de pinta-preta no fruto (PPF) avaliada na primeira época e de oídio em folha (SOM) estimada com base na média das duas épocas, segundo o método de Hayman (1954a,b)

\begin{tabular}{lccc} 
Parâmetros $^{(1)}$ & \multicolumn{3}{c}{ Valores dos parâmetros } \\
$\sqrt{\hat{\mathrm{H}}_{1} / \hat{\mathrm{D}}}$ & 0,3707 & 0,9568 & 0,9997 \\
$\hat{\mathrm{H}}_{2} / 4 \hat{\mathrm{H}}_{1}$ & $-0,1652$ & 0,1402 & 0,0551 \\
$\hat{\mathrm{K}}_{\mathrm{D}} / \hat{\mathrm{K}}_{\mathrm{R}}$ & 76,7880 & 2,2975 & 8,5140 \\
$\hat{\mathrm{h}}^{2} / \hat{\mathrm{H}}_{2}$ & 3,6380 & 1,2021 & 0,3734 \\
$\hat{\mathrm{h}}_{\mathrm{R}}^{2}$ & 0,2005 & 0,3305 & 0,1349 \\
$\hat{\mathrm{h}}_{\mathrm{A}}^{2}$ & 0,2007 & 0,4612 & 0,2092 \\
\hline
\end{tabular}

$\sqrt[(1)]{\hat{\mathrm{H}}_{1} / \hat{\mathrm{D}}}$ : grau médio de dominância; $\hat{\mathrm{H}}_{2} / 4 \hat{\mathrm{H}}_{1}$ : distância dos alelos (simetria); $\hat{\mathrm{K}}_{\mathrm{D}} / \hat{\mathrm{K}}_{\mathrm{R}}$ : relaçāo dominante/recessivo; $\hat{\mathrm{h}}^{2} / \hat{\mathrm{H}}_{2}$ : número de genes com dominância; $\hat{\mathrm{h}}_{\mathrm{R}}^{2}$ : coeficiente de determinação no sentido restrito; $\hat{\mathrm{h}}_{\mathrm{A}}^{2}$ : coeficiente de determinaçăo no sentido amplo
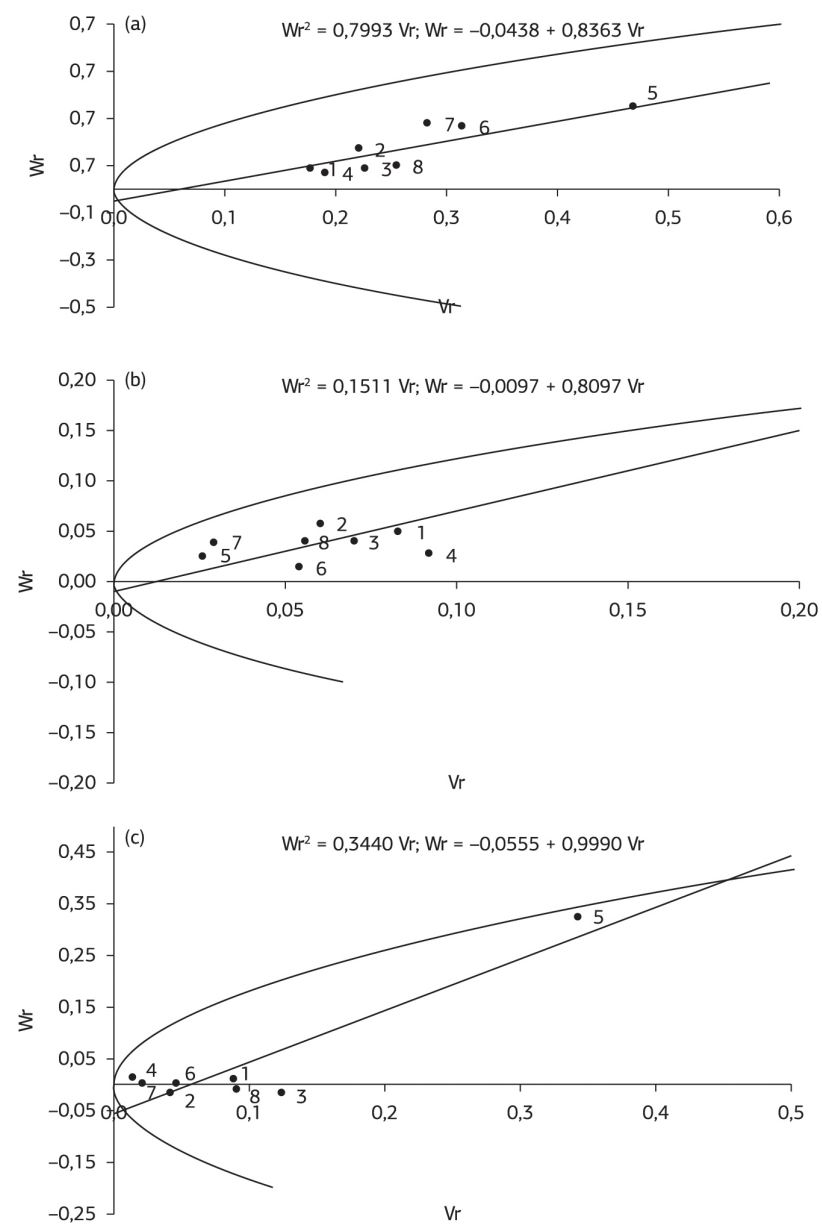

Figura 1. Regressóes de $\hat{\mathrm{W}}_{\mathrm{r}}$, em $\hat{\mathrm{V}}_{\mathrm{r}}$, nas severidades de oídio em folha (a), de pinta-preta em folha (b) e em fruto (c); genitores: 1 - Maradol; 2 - JS 12-N; 3 - JS 12-7; 4 - Sekati; 5 - Waimanalo; 6 - Golden; 7 Sunrise Solo 72-12 ; e 8 - São Mateus a existência de pelo menos quatro genes ou blocos gênicos para severidade de oídio e ao menos um gene ou bloco gene para severidade da pinta-preta em folha e em fruto (Tabela 2). Os valores das estimativas dos coeficientes de determinação genotípicos no sentido amplo e restrito revelam que, em sua maioria, os efeitos genéticos aditivos estão envolvidos no controle genético das características SOM, SPP e PPF (Tabela 2). Entretanto, como as estimativas de $\hat{\mathrm{D}}-\hat{\mathrm{H}}_{1}$ foram positivas mas não superaram o respectivo desvio padrão, conclui-se pela predominância de efeitos gênicos aditivos e náo aditivos no controle da pinta-preta em folha e em fruto (Tabela 3).

Para severidade de oídio (SOM), as correlaçôes (r) positivas e de moderada magnitude $(0,86)$ mostram que alelos dominantes, predominantes, mas não exclusivamente, atuam no sentido de reduzir a média dessa variável (Tabela 4). Os genitores Maradol e Sekati foram os que apresentaram maior concentraçáo de alelos dominantes, enquanto Waimanalo reteve maior concentração de alelos recessivos (Tabela 5). O genitor com máxima homozigose dominante para $\mathrm{SOM}$ deverá apresentar $\hat{\mathrm{W}}_{\mathrm{i}}+\hat{\mathrm{V}}_{\mathrm{i}}=-0,040\left(=\hat{\mathrm{W}}_{\mathrm{D}}+\hat{\mathrm{V}}_{\mathrm{D}}\right)$. Sekati, que apresentou o valor mais próximo $(0,2610)$, ainda está distante desse valor, indicando possibilidade de obtenção de linhagens com menor severidade de oídio nas populaçóes segregantes derivadas do dialelo. A diminuição de SOM pode ser obtida com a maior concentração de genes dominantes, sendo o valor máximo esperado $\left(\hat{Y}_{D}\right)$ de 0,611 . Maradol é o genitor que se encontra próximo desse valor (Tabela 4 e 5).

Para severidade de pinta-preta avaliada em folha, as correlaçôes $(r)$ positivas de baixa magnitude $(0,36)$ indicam que genes dominantes atuam para diminuir a expressão do caráter, mas de forma não exclusiva. Para essa característica apresentaram maior concentração de alelos dominantes os genótipos Waimanalo, Golden e Sunrise Solo 72-12, sendo esses, portanto, os mais favoráveis para obtenção de linhagens com baixos valores de severidade de pinta-preta em folha (Tabela 5). O genitor com máxima homozigose dominante para SPP deverá apresentar $\hat{\mathrm{W}}_{\mathrm{i}}+\hat{\mathrm{V}}_{\mathrm{i}}=-0,0086\left(=\hat{\mathrm{W}}_{\mathrm{D}}+\hat{\mathrm{V}}_{\mathrm{D}}\right)$. Com o valor de 0,0528 , Waimanalo foi o genitor com valor mais próximo, indicando ainda possibilidade de obtenção de linhagens com menor severidade de pinta-preta nas populaçôes segregantes derivadas do dialelo. A diminuição de SPP pode ser obtida com a maior concentração de genes dominantes, sendo o valor máximo esperado $\left(\hat{\mathrm{Y}}_{\mathrm{D}}\right)$ de 0,111 . Waimanalo, com média de 0,190 , foi o genitor que ficou mais próximo a esse valor, indicando que possui elevada concentração de genes dominantes (Tabela 4 e 5).

Para severidade de pinta-preta, avaliada em fruto, as correlaçốes (r) positivas e de magnitude de 0,99 mostram que alelos dominantes, predominantes, mas não exclusivamente, atuam no sentido de reduzir a média dessas variáveis (Tabela 4). Os genótipos com maior concentração de alelos dominantes foram Sunrise Solo 72-12, JS 12-N e Sekati, sendo, portanto, os mais favoráveis para obtenção 
de linhagens, com baixos valores de pinta-preta em fruto (Tabela 5). O genitor com máxima homozigose dominante deverá apresentar $\hat{\mathrm{W}}_{\mathrm{i}}+\hat{\mathrm{V}}_{\mathrm{i}}=-0,042\left(=\hat{\mathrm{W}}_{\mathrm{D}}+\hat{\mathrm{V}}_{\mathrm{D}}\right)$. Sunrise Solo $72-12$, que apresentou o valor mais próximo $(0,020)$, ainda está distante desse valor, indicando possibilidade de obtenção de linhagens com menor severidade de pinta-preta nas populaçôes segregantes derivadas do dialelo. A diminuição de PPF pode ser obtida com a maior concentração de genes dominantes, sendo o valor máximo esperado $\left(\hat{Y}_{D}\right)$ de -0,110. Com exceção de Waimanalo, os demais genitores

Tabela 3. Estimativa dos componentes genéticos e não genéticos da severidade de pinta-preta em folha (SPP) avaliada na segunda época, de pinta-preta no fruto (PPF) avaliada na primeira época e de oídio em folha (SOM) estimada com base na média das duas épocas, segundo o método de HaYMAN (1954a,b)

\begin{tabular}{|c|c|c|c|}
\hline \multirow{2}{*}{ Componentes $^{(1)}$} & \multicolumn{3}{|c|}{ Valores dos componentes \pm desvio padrão } \\
\hline & SOM & SPP & PPF \\
\hline$\hat{\varepsilon}$ & $0,397 \pm 0,032$ & $0,0523 \pm 0,011$ & $0,1271 \pm 0,019$ \\
\hline$\hat{\mathrm{D}}$ & $0,402 \pm 0,095$ & $0,0988 \pm 0,032$ & $0,2169 \pm 0,057$ \\
\hline$\hat{\mathrm{H}}_{1}$ & $0,055 \pm 0,218$ & $0,0905 \pm 0,074$ & $0,2167 \pm 0,130$ \\
\hline$\hat{\mathrm{H}}_{2}$ & $-0,037 \pm 0,190$ & $0,0507 \pm 0,065$ & $0,0478 \pm 0,113$ \\
\hline$\hat{\mathrm{h}}^{2}$ & $-0,133 \pm 0,127$ & $0,0610 \pm 0,043$ & $0,0178 \pm 0,076$ \\
\hline$\hat{\mathrm{F}}$ & $0,290 \pm 0,224$ & $0,0744 \pm 0,077$ & $0,3425 \pm 0,134$ \\
\hline$\hat{\mathrm{D}}-\hat{\mathrm{H}}_{1}$ & $0,347 \pm 0,187$ & $0,0084 \pm 0,064$ & $0,0001 \pm 0,112$ \\
\hline
\end{tabular}

Tabela 4. Estimativas das correlações entre os valores médios dos genitores $\left(\overline{\mathrm{Y}}_{\mathrm{rr}}\right)$ e da soma da covariância, entre médias dos genitores e médias da r-ésima linha $\left(\hat{\mathrm{W}}_{\mathrm{r}}\right)$, e da variância entre médias da r-ésima linha $\left(\hat{\mathrm{V}}_{\mathrm{r}}\right)$, valores esperados das coordenadas $\hat{\mathrm{W}}_{\mathrm{R}} ; \hat{\mathrm{V}}_{\mathrm{R}}$ e $\hat{\mathrm{W}}_{\mathrm{D}} ; \hat{\mathrm{V}}_{\mathrm{D}}$ e do valor predito para o genitor com máxima concentraçáo de alelos dominantes $\left(\hat{\mathrm{Y}}_{\mathrm{D}}\right)$ e recessivos $\left(\hat{\mathrm{Y}}_{\mathrm{R}}\right)$ da severidades de pinta-preta em folha (SPP) avaliada na segunda época, da pinta-preta no fruto (PPF) avaliada na primeira época e de oídio em folha (SOM) estimada com base na média das duas épocas, segundo o método de HaYMan (1954a,b)

\begin{tabular}{|c|c|c|c|}
\hline \multirow{2}{*}{ Parâmetros } & \multicolumn{3}{|c|}{ Estimativas dos parâmetros } \\
\hline & SOM & SPP & PPF \\
\hline $\mathrm{r}\left(\overline{\mathrm{Y}}_{\mathrm{rr}}, \hat{\mathrm{W}}_{\mathrm{r}}+\hat{\mathrm{V}}_{\mathrm{r}}\right)$ & 0,8601 & 0,3584 & 0,9924 \\
\hline$\hat{\mathrm{W}}_{\mathrm{R}} ; \hat{\mathrm{V}}_{\mathrm{R}}$ & 0,$9978 ; 1,2454$ & 0,$1959 ; 0,2540$ & 0,$3929 ; 0,4488$ \\
\hline$\hat{\mathrm{W}}_{\mathrm{D}} ; \hat{\mathrm{V}}_{\mathrm{D}}$ & $-0,0419 ; 0,0022$ & $-0,0093 ; 0,0006$ & $-0,0486 ; 0,0069$ \\
\hline Limite $\hat{\mathrm{Y}}_{\mathrm{R}}$ & 6,7764 & 1,7090 & 1,1558 \\
\hline Limite $\hat{\mathrm{Y}}_{\mathrm{D}}$ & 0,6107 & 0,1110 & $-0,1101$ \\
\hline
\end{tabular}

Tabela 5. Valores da soma da covariância entre médias dos genitores e médias da r-ésima linha $\left(\hat{\mathrm{W}}_{\mathrm{r}}\right)$, e da variância entre médias da r-ésima linha $\left(\hat{\mathrm{V}}_{\mathrm{r}}\right)$ e médias da severidade de pinta-preta em folha (SPP) avaliada na segunda época, da pinta-preta no fruto (PPF) avaliada na primeira época e de oídio em folha (SOM) estimada com base na média das duas épocas, segundo o método de HaYman (1954a,b)

\begin{tabular}{|c|c|c|c|c|c|c|}
\hline \multirow{2}{*}{ Genótipos } & \multicolumn{2}{|c|}{ SOM } & \multicolumn{2}{|c|}{ SPP } & \multicolumn{2}{|c|}{ PPF } \\
\hline & $\hat{\mathrm{W}}_{\mathrm{r}+} \hat{\mathrm{V}}_{\mathrm{r}}$ & média & $\hat{\mathrm{W}}_{\mathrm{r}+}+\hat{\mathrm{V}}_{\mathrm{r}}$ & média & $\hat{\mathrm{W}}_{\mathrm{r}+\hat{\mathrm{V}}_{\mathrm{r}}}$ & média \\
\hline Maradol & 0,265 & 0,860 & 0,133 & 0,488 & 0,094 & 0,088 \\
\hline JS 12-N & 0,391 & 1,610 & 0,117 & 0,193 & 0,025 & 0,018 \\
\hline JS $12-4$ & 0,317 & 2,118 & 0,110 & 0,328 & 0,104 & 0,038 \\
\hline Sekati & 0,261 & 1,510 & 0,120 & 1,068 & 0,025 & 0,015 \\
\hline Waimanalo & 0,820 & 2,918 & 0,053 & 0,190 & 0,665 & 0,915 \\
\hline Golden & 0,583 & 2,245 & 0,068 & 0,425 & 0,049 & 0,020 \\
\hline Sunrise Solo 72/12 & 0,559 & 2,235 & 0,067 & 0,440 & 0,020 & 0,018 \\
\hline São Mateus & 0,350 & 1,828 & 0,095 & 0,663 & 0,082 & 0,013 \\
\hline
\end{tabular}


encontram-se próximos desse valor, indicando que possuem elevada concentração de genes dominantes (Tabela 4 e 5).

\section{CONCLUSÃO}

A redução da severidade da pinta-preta em folha e em fruto e da severidade do oídio em folha são controladas por genes dominantes. Há ao menos um gene ou bloco gênico com dominância para característica que confere resistência à pinta-preta em folha e em fruto e ao menos quatro para resistência à oídio. A severidade de pinta-preta em folha e em fruto apresenta dominância completa, enquanto que na severidade de oídio em folha há dominância parcial. Sekati foi o genitor que apresentou a maior concentração de alelos favoráveis para a redução da severidade de pinta-preta em folha e em fruto e da severidade de oídio em folha.

\section{AGRADECIMENTOS}

À Fundação Carlos Chagas Filho de Amparo à Pesquisa do Estado do Rio de Janeiro (FAPERJ), à Universidade Estadual do Norte Fluminense Darcy Ribeiro (UENF) e à Caliman Agrícola S/A pelo suporte financeiro e logístico.

\section{REFERÊNCIAS}

CRUZ, C.D. GENES - a software package for analysis in experimental statistics and quantitative genetics. Acta Scientiarum. Agronomy, v.35, p.271-276, 2013.

CRUZ, C.D.; REGAZZI, A.J.; CARNEIRO, P.C. Modelos biométricos aplicados ao melhoramento genético. Viçosa: Editora UFV, 2012. 514p.

DIANESE, A.C.; BLUM, L.E.B.; DUTRO, J.B.; LOPES, L.F.; SENA, M.C.; FREITAS, L.F.; YAMANISHI, O.K. Reação de genótipos de mamoeiro à varíola e à podridão-do-pé. Fitopatologia Brasileira, v.32, p.419-423, 2007. http://dx.doi.org/10.1590/S010041582007000500008

GARDNER, C.O.; EBERHART, S.A. Analysis and interpretation of the variety cross diallel and related populations. Biometrics, v.22, p.439-452, 1966. http://dx.doi.org/10.2307/2528181

GRIFFING, B.A. Concept of general and specific combining ability in relation to diallel crossing systems. Australian Journal of Biological Sciences, v.9, p.463-493, 1956.

HAYMAN, B.I. The analysis of variance of diallel tables. Biometrics, v.10, p.235-244, 1954a. http://dx.doi.org/10.2307/3001877
HAYMAN, B.I. The theory and analysis of diallel crosses. Genetics, v.39, p.789-809, $1954 b$.

JINKS, J.L.; HAYMAN, B.I. The analysis of diallel crosses. Maize Genetics Cooperation Newsletter, v.27, p.48-54, 1953.

LIBERATO, J.R.; BARRETO, R.W.; LOURO, R.P. Streptopodium caricae sp. nov., with a discussion of powdery mildews on papaya, and emended descriptions of the genus Streptopodium and Oidium caricae. Mycology Research, v.18, p.1185-1194, 2004. http://dx.doi. org/10.1017/S0953756204000991

REZENDE, J.A.M.; MARTINS, M.C. Doenças do mamoeiro (Caricapa paya L.). In: KIMATI, H.; AMORIM, L.; REZENDE, J.A.M.; BERGAMIN FILHO, A.; CAMARGO, L.E.A. Manual de fitopatologia: Doenças das plantas cultivadas. 4. ed. São Paulo: Agronômica Ceres, 2005. cap.49, p.435-443.

SANTOS, P.H.D.; VIVAS, M.; SILVEIRA, S.F.; SILVA, J.M.; TERRA, C.E.P.S. Elaboração e validaçáo de escala diagramática para avaliaçáo da severidade de oídio em folhas de mamoeiro. Summa Phytopathologica, v.37, p.215-217, 2011. http://dx.doi.org/10.1590/ S0100-54052011000400011

VENCOVSKY, R.; BARRIGA, P. Genética biométrica no fitomelhoramento. Ribeirão Preto: Sociedade Brasileira de Genética, 1992. 486 p.

VIVAS, M.; SILVEIRA, S.F.; CARDOSO, D.L.; PEREIRA, M.G.; SANTOS, P.H.D.; FERREGUETTI, G.A. Capacidade Combinatória e heterose para resistência a pinta-preta em mamoeiro por meio de análise dialélica. Tropical Plant Pathology, v.37, p.326-332, 2012a. http://dx.doi.org/10.1590/S1982-56762012000500004

VIVAS, M.; SILVEIRA, S.F.; CARDOSO, D.L.; PEREIRA, M.G.; VIVAS, J.M.S.; FERREGUETTI, G.A. Capacidade combinatória em mamoeiro para resistência a oídio. Bragantia, v.71, p.455-459, 2012b. http://dx.doi.org/10.1590/S0006-87052012000400001

VIVAS, M.; SILVEIRA, S.F.; PEREIRA, M.G.; CARDOSO, D.L.; FERREGUETTI, G.A. Análise dialélica em mamoeiro para resistência a mancha-de-phoma. Ciência Rural, v.43, p.945-950, 2013. http:// dx.doi.org/10.1590/S0103-84782013005000054

VIVAS, M.; SILVEIRA, S.F.; TERRA, C.E.P.S.; PEREIRA, M.G. Reação de germoplasma e híbridos de mamoeiro à mancha-dephoma (Phoma caricae-papayae) em condiçóes de campo. Tropical Plant Pathology, v.35, p.323-328, 2010a. http://dx.doi.org/10.1590/ S1982-56762010000500009

VIVAS, M.; SILVEIRA, S.F.; VIVAS, J.M.S.; PEREIRA, M.G. Patometria, parâmetros genéticos e reaçáo de progênies de mamoeiro à pinta-preta. Bragantia, v.71, p.235-238, 2012c. http://dx.doi. org/10.1590/S0006-87052012005000021

VIVAS, M.; TERRA, C.E.P.S.; SILVEIRA, S.F.; FONTES, R.V.; PEREIRA, M.G. Escala diagramática para avaliação da severidade de pinta-preta em frutos de mamoeiro. Summa Phytopathologica, v.36, p.161-163, 2010b. http://dx.doi.org/10.1590/S010054052010000200010 